\title{
Níveis de fitase sobre o desempenho, parâmetros ósseos e bioquímicos de suínos alimentados com ração de origem vegetal sem inclusão de fosfato bicálcico
}

\author{
Phytase levels on performance, bone and biochemical parameters of pigs fed \\ with diet of vegetable origin without inclusion of dicalcium phosphate
}

\author{
João Gabriel Pereira Magnago ${ }^{\mathrm{I}}$ Douglas Haese $^{\mathrm{I} \mathrm{I}^{*}}$ João Luís Kill ${ }^{\mathrm{II}}$ \\ Rodrigo Pereira SobreiroI Débora Del Puppo ${ }^{I}$ Dawster Sant'anna ${ }^{I}$ \\ Alysson Saraiva ${ }^{\mathrm{III}}$ Lucas Lemke Lorenzoni ${ }^{\mathrm{I}}$ Rafael Bozani Pimentel $^{\mathrm{I}}$
}

\section{RESUMO}

Este estudo foi conduzido com o objetivo de avaliar os níveis de fitase em rações para suínos em crescimento selecionados para deposição de carne. Foram utilizados 64 suinos mestiços (32 machos castrados e 32 fêmeas), híbridos comerciais, com peso médio inicial de 23,311 $\pm 2,254 \mathrm{~kg}$, distribuidos em delineamento de blocos casualizados, com quatro tratamentos, oito repetições e dois animais (um macho e uma fêmea) por unidade experimental. Os tratamentos foram constituídos por uma ração controle de origem vegetal, sem inclusão de fosfato bicálcico e fitase, contendo $0,100 \%$ de fósforo disponivel; e de outras três rações obtidas pela inclusão de 300, 600 e 1200 unidades de fitase (UFT $\mathrm{kg}^{-1}$ ) à ração controle. Os níveis de fitase influenciaram de forma linear o ganho de peso diário e consumo de ração, aumentando até o nível de 293 e 307 UFT kg-1 de ração, respectivamente, a partir do qual permaneceram em um platô. A conversão alimentar diminuiu até $255 \mathrm{UFT}_{\mathrm{kg}^{-1}}$ de ração, a qual permaneceu em um platô. Os niveis de fitase não influenciaram os teores de cinzas e fósforo no metacarpo dos animais. Houve efeito linear decrescente dos tratamentos sobre o resultado bioquímico de fosfatase alcalina. Os melhores resultados de ganho de peso, consumo de ração e conversão alimentar foram obtidos, respectivamente, com os níveis de 293, 307 e $255 \mathrm{UFT} \mathrm{kg}^{-1}$ de ração, em suínos de alto potencial genético para deposição de carne na fase dos 55 aos 90 dias de idade.

Palavras-chave: cálcio e fósforo, desempenho, enzima, ração, suinocultura.

\section{ABSTRACT}

This study was carried out to determine the phytase levels in diets for growing swine selected for meat deposition. Sixty-four crossbred swine (32 barrows and 32 females), with an average initial weight of $23.311 \pm 2.254 \mathrm{~kg}$ were distributed in a block design with four treatments and eight replications of two animals (one male and one female) each. The treatments consisted of a control diet with vegetables ingredients, without dicalcium phosphate and phytase inclusion, containing $0.100 \%$ available phosphorus and three other diets obtained by the inclusion of 300, 600 and 1200 phytase units $\left(F T U \mathrm{~kg}^{-1}\right)$ to the control diet. Levels of phytase influenced linearly the daily weight gain and feed intake, increasing to the level of 293 and 307 FTU $\mathrm{kg}^{-1}$ diet, respectively, from which remained on a plateau. Feed conversion ratio decreased to $255 \mathrm{FTU}_{\mathrm{kg}^{-1}}$ diet, and remained on a plateau. Levels of phytase did not affect the levels of ash and phosphorus in animal bone. There was decreasing linear effect of treatments on the biochemical results of alkaline phosphatase. The best results in weight gain, feed intake and feed conversion were obtained, respectively, with levels of 293, 307 and 255 FTU $\mathrm{kg}^{-1}$ of feed for pigs of high genetic potential for lean deposition during the 55 to 90 days of age.

Key words: calcium and phosphorus, development, enzyme, feed, swine production.

\section{INTRODUÇ̃̃O}

As exigências de cálcio $(\mathrm{Ca})$ e fósforo (P) na nutrição de monogástricos são comumente supridas através da inclusão de calcário calcítico, fosfato bicálcico ou farinha de carne e ossos. Os ingredientes vegetais, apesar de não serem a principal fonte de minerais para aves e suínos, apresentam uma quantidade considerável de fósforo (SELLE et al., 2009), no entanto, apenas $1 / 3$ deste mineral está disponível para os animais após a

\footnotetext{
'Mestrando em Ciência Animal, Universidade Vila Velha (UVV), Vila Velha, ES, Brasil.

IIPrograma de Mestrado em Ciência Animal, UVV, 29102-606, Vila Velha, ES, Brasil. E-mail: douglas.haese@uvv.br. *Autor para correspondência.

IIIUniversidade Federal de Viçosa (UFV), Viçosa, MG, Brasil. 
digestão, pois o fósforo está ligado à molécula de ácido fítico, o qual não é completamente aproveitado pelos animais monogástricos (FIREMAN et al., 1998; SELLE et al., 2009).

O ácido fítico ou fitato não indisponibiliza apenas o fósforo presente nos cereais, ele também é capaz de se complexar com alguns cátions bivalentes como $\mathrm{Ca}, \mathrm{Fe}, \mathrm{Mg}$ e $\mathrm{Zn}$, com grupos $\alpha-\mathrm{NH}_{2}$ de aminoácidos, como a lisina, histidina e arginina, além de inibir a atividade da tripsina e pepsina (FIREMAN et al., 1998). Devido à capacidade de indisponibilizar alguns minerais e aminoácidos, o fitato pode afetar negativamente o desempenho destes animais, de maneira a proporcionar uma queda no ganho de peso, e ainda piorar a conversão alimentar.

Devido a estes fatores, vários nutricionistas vêm utilizando enzimas para melhorar a digestibilidade dos nutrientes, sendo a fitase uma delas. A adição de fitase em dietas de suínos e aves tem como principal vantagem a liberação do fósforo inorgânico, ligado à molécula de ácido fítico, consequentemente, reduzindo-se a necessidade de se utilizar fontes de fósforo inorgânico nas dietas. Além de melhorar a disponibilidade do fósforo, é possível que outros minerais como $\mathrm{Ca}, \mathrm{Mg}, \mathrm{Cu}, \mathrm{Fe}$ e Zn, e alguns aminoácidos tenham sua disponibilidade melhorada (ADELOA et al., 1995). A adição de fitase, por melhorar a disponibilidade dos nutrientes, pode aumentar o ganho de peso e eficiência alimentar (JONES et al., 2010). Assim, este trabalho foi realizado com o objetivo de avaliar níveis de fitase sobre o desempenho, parâmetros ósseos e bioquímicos de suínos de alto potencial genético, alimentados com ração de origem vegetal, sem inclusão de fosfato bicálcico, no período de 55 a 90 dias de idade.

\section{MATERIAL E MÉTODOS}

O estudo foi realizado no Setor de Suinocultura do Centro de Tecnologia Animal CTA, localizado no distrito de Paraju, município de Domingos Martins, Espírito Santo. Foram utilizados 64 suínos mestiços (32 machos castrados e 32 fêmeas) de linhagem genética Agroceres PIC $^{\circledR}$ com alto potencial para deposição de carne e peso inicial médio de 23,311 $\pm 2,254 \mathrm{~kg}$.

Os suínos foram alojados em baias com piso de concreto, dotadas de comedouros semiautomáticos e bebedouros tipo chupeta, localizadas em prédio de alvenaria, coberto com telhas de cerâmica.

Os animais foram distribuídos em delineamento de blocos casualizados, com quatro tratamentos, oito repetições e dois animais (um macho e uma fêmea) por unidade experimental. As rações experimentais foram elaboradas a base de milho e de farelo de soja, e suplementadas com aminoácidos industriais, para atender às exigências nutricionais dos suínos na fase de crescimento. Com exceção do fósforo disponível, que foi mantido no nível de $0,100 \%$, todos os nutrientes atendiam às exigências preconizadas por ROSTAGNO et al. (2011).

Os tratamentos consistiram numa ração controle farelada, sem inclusão de fosfato bicálcico e fitase, contendo $0,100 \%$ de fósforo disponível; e de outras três rações obtidas pela inclusão de 300, 600 e 1200 unidades de fitase (UFT $\mathrm{kg}^{-1}$ ) à ração controle (Tabela 1). As rações experimentais foram fornecidas por um período de 35 dias. A água e a ração foram fornecidas à vontade aos animais.

No último dia do experimento, foram coletadas amostras de sangue para análises bioquímicas de cálcio $(\mathrm{Ca})$, fósforo $(\mathrm{P})$ e fosfatase alcalina (FA) de seis animais por tratamento. As amostras foram colhidas através da punção da veia cefálica, com o auxílio de seringas de $3,0 \mathrm{~mL}$, agulha $25 \mathrm{~mm} \times 8 \mathrm{~mm}$, e tubos estéreis sem anticoagulante. Após a coleta, as amostras foram centrifugadas a 1000rpm durante 15 minutos, para obtenção do soro sanguíneo. A análise de fosfatase alcalina foi obtida pelo método enzimático UV (AMP-IFCC), descrito por BOWERS \& McCOMB (1966), e o fósforo e cálcio pelo método IR colorimétrico/catalizado, ambos determinados em espectofotômetro $(405 \mathrm{~nm}$ e 600-700nm, respectivamente).

No final do período experimental, após jejum de 12 horas, cinco animais por tratamento, com peso mais próximo da média, foram abatidos para coleta da pata anterior direita. O abate foi realizado de forma humanitária, com a insensibilização através de choque elétrico de alta voltagem e baixa amperagem, atrás das orelhas do animal (fossas temporais). A sangria foi realizada após a insensibilização em no máximo 30 segundos por meio de seccionamento dos grandes vasos ou punção diretamente no coração.

As patas coletadas foram colocadas em recipiente de alumínio contendo água e fervidas, por 25 minutos, visando ao amolecimento da pele e da carne que envolve os ossos para a retirada do terceiro osso metacarpiano. O metacarpo de cada animal abatido foi mantido em estufa ventilada a $65^{\circ} \mathrm{C}$ durante 72 horas e, então, submetidos à quebra. Depois de quebrados, os ossos foram desengordurados em extrator Soxhlet e levados novamente à estufa ventilada a $105^{\circ} \mathrm{C}$ durante 24 horas e, em seguida, foram triturados em moinho 
Tabela 1 - Composição das rações experimentais.

\begin{tabular}{|c|c|c|c|c|}
\hline \multirow{2}{*}{ Ingrediente $(\%)$} & \multicolumn{4}{|c|}{ 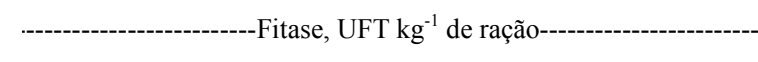 } \\
\hline & 0,00 & 300 & 600 & 1200 \\
\hline Milho & 73,700 & 73,700 & 73,700 & 73,700 \\
\hline Farelo de soja & 22,600 & 22,600 & 22,600 & 22,600 \\
\hline Óleo de soja & 0,400 & 0,400 & 0,400 & 0,400 \\
\hline Calcário calcítico & 1,600 & 1,600 & 1,600 & 1,600 \\
\hline Cloreto de sódio & 0,400 & 0,400 & 0,400 & 0,400 \\
\hline Lisina $\mathrm{HCl} 78 \%$ & 0,285 & 0,285 & 0,285 & 0,285 \\
\hline DL-Metionina 98\% & 0,060 & 0,060 & 0,060 & 0,060 \\
\hline Treonina 98\% & 0,070 & 0,070 & 0,070 & 0,070 \\
\hline Cloreto de colina $60 \%$ & 0,050 & 0,050 & 0,050 & 0,050 \\
\hline Premix vitamínico ${ }^{1}$ & 0,100 & 0,100 & 0,100 & 0,100 \\
\hline Premix mineral $^{2}$ & 0,100 & 0,100 & 0,100 & 0,100 \\
\hline Sulfato de colistina $50 \%$ & 0,008 & 0,008 & 0,008 & 0,008 \\
\hline Melhorador de desempenho ${ }^{3}$ & 0,006 & 0,006 & 0,006 & 0,006 \\
\hline Fitase $^{4}$ & 0,000 & 0,005 & 0,010 & 0,020 \\
\hline Inerte (Caulin) & 0,621 & 0,616 & 0,611 & 0,601 \\
\hline Energia metabolizável, kcal/kg & 3230 & 3230 & 3230 & 3230 \\
\hline Proteína bruta, $\%$ & 16,66 & 16,66 & 16,66 & 16,66 \\
\hline Lisina digestível, \% & 0,940 & 0,940 & 0,940 & 0,940 \\
\hline Metionina + cistina digestível, $\%$ & 0,560 & 0,560 & 0,560 & 0,560 \\
\hline Treonina digestível, \% & 0,610 & 0,610 & 0,610 & 0,610 \\
\hline Triptofano digestível, \% & 0,170 & 0,170 & 0,170 & 0,170 \\
\hline Arginina digestível, \% & 1,000 & 1,000 & 1,000 & 1,000 \\
\hline Sódio, \% & 0,180 & 0,180 & 0,180 & 0,180 \\
\hline Cálcio, \% & 0,700 & 0,700 & 0,700 & 0,700 \\
\hline Cálcio analisado, \% & 0,687 & 0,687 & 0,687 & 0,687 \\
\hline Fósforo total, $\%$ & 0,310 & 0,310 & 0,310 & 0,310 \\
\hline Fósforo analisado, \% & 0,301 & 0,301 & 0,301 & 0,301 \\
\hline Fósforo disponível, \% & 0,100 & 0,100 & 0,100 & 0,100 \\
\hline Relação cálcio/fósforo analisado & 2,28 & 2,28 & 2,28 & 2,28 \\
\hline
\end{tabular}

${ }^{1}$ Conteúdo $\mathrm{kg}^{-1}$ : niacina 13.000mg; vitamina A 2.666.000UI; vitamina B2 1.600mg; biotina 16,56mg; colina 120.000mg; ácido fólico 266mg;

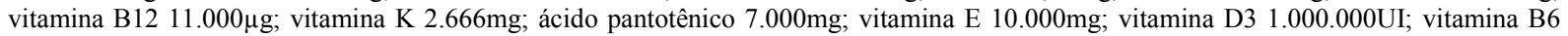
$666 \mathrm{mg}$; antioxidante $2.160 \mathrm{mg}$; veículo q.s.p. $1.000 \mathrm{~g}$.

${ }^{2}$ Conteúdo $\mathrm{kg}^{-1}$ : selênio $130 \mathrm{mg}$; manganês $40.020 \mathrm{mg}$; cobre $15.000 \mathrm{mg}$; ferro $24.930 \mathrm{mg}$; cobalto $168 \mathrm{mg}$; iodo $1.416,8 \mathrm{mg}$; zinco $74.971 \mathrm{mg}$; veículo q.s.p. $1.000 \mathrm{~g}$.

${ }^{3}$ Enramicina $8 \%$.

${ }^{4}$ Enzima contendo 6000 UFT g $^{-1}$.

de bola (SARAIVA et al., 2009a). As análises dos teores de cinzas nos ossos $(\mathrm{CO})$ e fósforo $(\mathrm{P})$ foram realizadas de acordo com a técnica descrita por SILVA \& QUEIROZ (2006), no laboratório Clóvis, Bárbara e Oneida (CBO) análises laboratoriais (Campinas, São Paulo).

As análises estatísticas foram realizadas utilizando-se os procedimentos para análise de variância e regressão, contidos no programa Sistema para Análises Estatísticas e Genéticas
(SAEG), desenvolvido na Universidade Federal de Viçosa (UFV, 2000), versão 8.0. As características de desempenho e as análises bioquímicas foram interpretadas por meio de análise de variância e regressão ao nível de $5 \%$ de probabilidade. As estimativas dos níveis de fitase foram determinadas por meio de modelos de regressão linear, quadrático ou Linear Response Plateau (LRP), descritos por BRAGA (1983), conforme o melhor ajustamento dos dados para cada variável. 


\section{RESULTADOS E DISCUSSÃO}

Houve efeito $(\mathrm{P}<0,05)$ dos níveis de fitase sobre o ganho de peso diário dos animais (Tabela 2), que aumentou de forma linear conforme os níveis de fitase nas rações. No entanto, o modelo Linear Response Plateau (LRP) foi o que melhor se ajustou aos dados, estimando em $293 \mathrm{UFT} \mathrm{kg}^{-1}$ de ração o nível de fitase, a partir do qual o ganho de peso diário permaneceu em um platô (Figura 1).

JENDZA et al. (2005), avaliando a inclusão de 500 e 1000 UFT kg-1 em rações de suínos com $0,07 \%$ de fósforo disponível na fase de crescimento, encontraram aumento linear sobre ganho peso dos animais. Por outro lado, VARLEY et al. (2011), estudando níveis de fósforo, cálcio e a inclusão de fitase em rações para suínos, na fase de crescimento (11 a $30 \mathrm{~kg}$ ), não observaram efeito sobre o ganho de peso diário com a inclusão de $500 \mathrm{UFT} \mathrm{kg}^{-1} \mathrm{em}$ rações com 0,$45 ; 0,55$; e $0,64 \%$ de fósforo total.

$\mathrm{O}$ consumo de ração e a conversão alimentar foram influenciados $(\mathrm{P}<0,05)$ de forma linear pelos níveis de fitase na ração (Tabela 2), que melhoraram conforme se aumentaram os níveis de fitase. De forma semelhante ao observado sobre o ganho de peso diário, o modelo Linear Response Plateau (LRP) foi o que melhor se ajustou aos dados, estimando em 307 e 255 UFT kg-1 de ração, respectivamente, o nível de fitase para consumo de ração e conversão alimentar.

O fósforo é um dos minerais mais importantes para suínos, pois desempenha várias funções no organismo e sua deficiência pode causar redução no consumo de ração e na eficiência alimentar (UNDERWOOD \& SUTLLE, 1999). SARAIVA et al. (2009b), trabalhando com níveis de fósforo disponível variando de 0,114 a $0,649 \%$, em rações de suínos dos 15 aos $30 \mathrm{~kg}$, observaram aumento linear no consumo de ração com o aumento nos níveis de fósforo.

Corroborando esses resultados, no presente estudo, houve $(\mathrm{P}<0,05)$ um menor consumo de ração no tratamento sem fitase; porém, a partir da inclusão da enzima, independente do nível, pode-se observar aumento no consumo de ração dos animais. Apesar da resposta positiva frente à utilização da enzima, podese constatar que os níveis de fitase determinados neste estudo tanto para consumo de ração, ganho de peso e conversão alimentar, estão abaixo dos 500 UFT kg-1 recomendados por RODRIGUES et al. (2011) para suínos de alto potencial genético.

Os níveis de fitase determinados no presente estudo para ganho de peso, consumo de ração e conversão alimentar podem ter sido influenciados pela relação cálcio/fósforo das rações $(2,28)$, uma vez que a adição de fitase pode liberar o cálcio indisponibilizado pelo fitato, extrapolando o nível recomendado. Alguns estudos têm mostrado que dietas formuladas com baixo nível de fósforo total e suplementadas com fitase têm reduzido a atividade da enzima, possivelmente devido ao desbalanceamento da relação cálcio e fósforo (QUIAN et al., 1996; APPLEGATE et al., 2003). De acordo com o que foi discutido, pode-se supor que a suplementação de 600

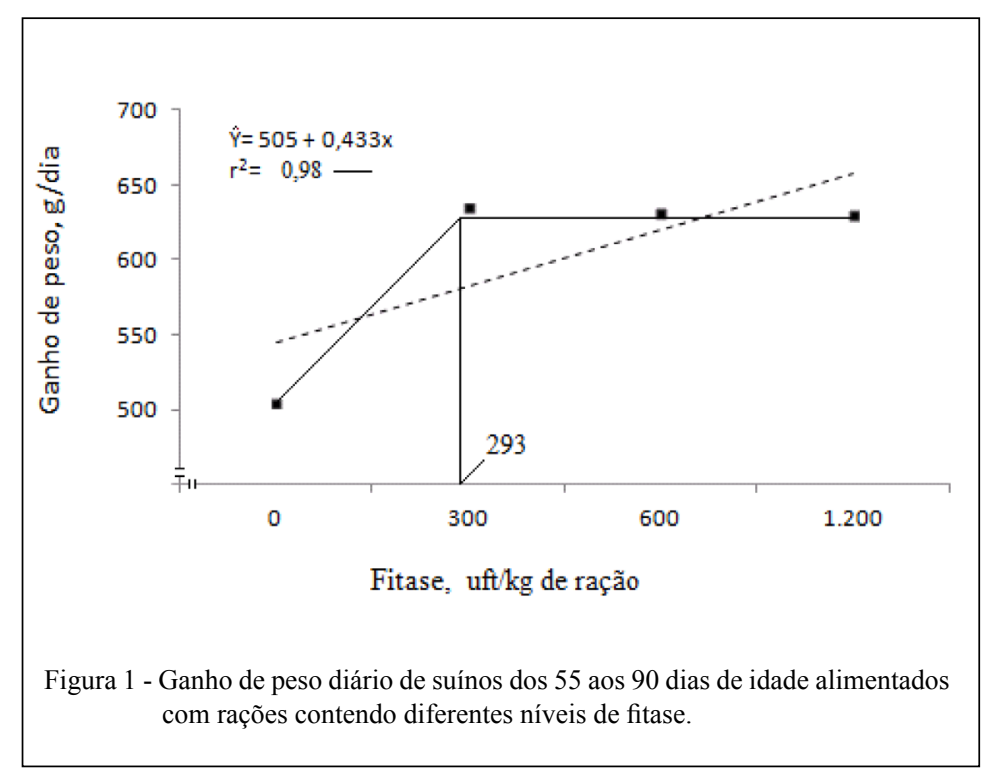

Ciência Rural, v.45, n.7, jul, 2015. 
Tabela 2 - Variáveis de desempenho de suínos recebendo diferentes níveis de fitase na ração dos 55 aos 90 dias de idade.

\begin{tabular}{|c|c|c|c|c|c|c|c|c|c|c|}
\hline \multirow{3}{*}{$\begin{array}{l}\text { Variável } \\
\text { Peso médio inicial }(\mathrm{kg})\end{array}$} & \multicolumn{8}{|c|}{ Inclusão de Fitase (UFT kg-1 de ração) } & \multirow{3}{*}{$\begin{array}{c}\mathrm{P}^{2} \\
0,450\end{array}$} & \multirow{3}{*}{$\begin{array}{l}\mathrm{CV}^{3}, \% \\
10,29\end{array}$} \\
\hline & \multicolumn{2}{|c|}{--------0,00-------- } & \multicolumn{2}{|c|}{--------300-------- } & \multicolumn{4}{|c|}{-----------600----------- ---------1200---------- } & & \\
\hline & 23,29 & $\pm 2,36$ & 23,28 & $\pm 2,38$ & 23,28 & $\pm 2,38$ & 23,40 & $\pm 2,47$ & & \\
\hline Ganho de peso $\left(\mathrm{g} \mathrm{dia}^{-1}\right)^{1}$ & 505 & \pm 38 & 635 & \pm 45 & 632 & \pm 68 & 631 & \pm 95 & 0,001 & 10,88 \\
\hline Consumo de ração $\left(\mathrm{g} \mathrm{dia}^{-1}\right)^{1}$ & 1328 & \pm 119 & 1537 & \pm 151 & 1534 & \pm 122 & 1550 & \pm 217 & 0,013 & 10,59 \\
\hline Consumo de Pd $\left(\mathrm{g} \mathrm{dia}^{-1}\right)^{1}$ & 1,33 & \pm & 1,54 & \pm & 1,53 & \pm & 1,55 & \pm & 0,007 & 8,68 \\
\hline Conversão alimentar $\left(\mathrm{g} \mathrm{g}^{-1}\right)^{1}$ & 2,63 & $\pm 0,16$ & 2,42 & $\pm 0,11$ & 2,43 & $\pm 0,09$ & 2,47 & $\pm 0,19$ & 0,042 & 5,73 \\
\hline
\end{tabular}

${ }^{1}$ Efeito linear; ${ }^{2}$ Probabilidade; ${ }^{3}$ Coeficiente de variação.

e 1200 UFT $\mathrm{kg}^{-1}$ em rações deficientes em fósforo $(0,100 \%$ disponível) promoveram a hidrólise da molécula de fitato, aumentando a disponibilidade do fósforo e de outros nutrientes, como o cálcio. Assim, esse aumento na quantidade de cálcio, provavelmente, reduziu a disponibilidade do fósforo hidrolisado da molécula de fitato. Segundo QUIAN et al. (1996), a suplementação de fitase nas rações de suínos deve ser feita com a relação cálcio e fósforo próxima de 1,2:1,0. Quando a relação está acima de $2: 1$, são formados complexos insolúveis, prejudicando a absorção dos nutrientes pelo animal. Dessa forma, os maiores níveis de fitase, no presente estudo, podem ter aumentado a relação cálcio e fósforo, prejudicando os benefícios da suplementação.

Os níveis de fitase não influenciaram $(\mathrm{P}>0,05)$ os teores de cinzas e fósforo no metacarpo dos animais (Tabela 3). Como os níveis de fósforo em todos os tratamentos estavam baixos $(0,100 \%$ de fósforo disponível), provavelmente, o fósforo liberado pela enzima fitase tenha sido utilizado para crescimento em detrimento à deposição óssea. Considerando os resultados de ganho peso dos animais neste trabalho, pode-se constatar que os animais consumindo a ração com fitase, indepentente do nível, tiveram um desempenho $25 \%$ superior aos animais que não consumiram a ração com fitase. Segundo SARAIVA et al. (2009a), animais selecionados geneticamente para deposição de músculo privilegiam o ganho de peso em detrimento da integridade óssea, quando submetidos à deficiência de fósforo.

Houve $(\mathrm{P}<0,05)$ efeito dos tratamentos sobre o resultado bioquímico da fosfatase alcalina, que reduziu de forma linear com a inclusão da enzima fitase (Tabela 3). Já os valores de cálcio e fósforo séricos não diferiram entre os tratamentos.

JENDZA et al. (2005), avaliando níveis de fósforo e a inclusão da enzima fitase em rações para suínos durante a fase de crescimento e terminação, não observaram diferenças no valor sérico do fósforo entre os tratamentos, que, segundo os autores, pode ter sido promovida pela maior reserva desse mineral nos animais nessa fase. Este resultado é semelhante ao observado no presente estudo, uma vez que não houve efeito $(\mathrm{P}>0,05)$ dos tratamentos em relação ao

Tabela 3 - Influência dos níveis de fitase em rações de suínos, dos 55 aos 90 dias de idade, sobre os teores de fósforo e cinzas no metacarpo e parâmetros bioquímicos de fosfatase alcalina $(\mathrm{FA})$, cálcio $(\mathrm{Ca})$ e fósforo $(\mathrm{P})$.

\begin{tabular}{|c|c|c|c|c|c|c|c|c|c|c|}
\hline \multirow{2}{*}{ Parâmetros } & \multicolumn{8}{|c|}{--------------------------------Inclusão de Fitase (FTU kg ${ }^{-1}$ de ração)------ } & \multirow{2}{*}{$\mathrm{P}^{2}$} & \multirow{2}{*}{$\mathrm{CV}^{3}, \%$} \\
\hline & \multicolumn{2}{|c|}{-----------0,00----------- } & \multicolumn{2}{|c|}{------------300------------ } & \multicolumn{2}{|c|}{------------600------------ } & \multicolumn{2}{|c|}{-----------1200----------. } & & \\
\hline ------------------------- & ----- & 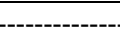 & ------- & ------Ósse & 1 & 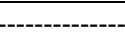 & & & & \\
\hline Cinzas $(\%)$ & 57,71 & $\pm 2,43$ & 59,08 & $\pm 1,04$ & 59,73 & $\pm 1,66$ & 58,95 & $\pm 1,74$ & 0,371 & 3,03 \\
\hline Fósforo (mg kg ${ }^{-1}$ ) & 99,10 & $\pm 4,70$ & 98,90 & $\pm 1,10$ & 103,4 & $\pm 4,20$ & 99,9 & $\pm 2,00$ & 0,149 & 3,34 \\
\hline FA, $\left(\mathrm{UI} \mathrm{L}^{-1}\right)^{4}$ & 197,23 & $\pm 106,08$ & 143,78 & $\begin{array}{l}\text {--Bioquím } \\
\pm 60,12\end{array}$ & 172,77 & $\pm 29,38$ & 147,37 & $\pm 51,26$ & 0,004 & 12,09 \\
\hline $\mathrm{Ca}\left(\mathrm{mg} \mathrm{dL}^{-1}\right)$ & 11,16 & $\pm 0,85$ & 10,50 & $\pm 0,64$ & 10,72 & $\pm 1,24$ & 10,82 & $\pm 0,63$ & 0,250 & 8,10 \\
\hline $\mathrm{P},\left(\mathrm{mg} \mathrm{dL}^{-1}\right)$ & 6,98 & $\pm 0,71$ & 8,12 & $\pm 2,04$ & 8,27 & $\pm 1,20$ & 7,62 & $\pm 1,11$ & 0,374 & 17,50 \\
\hline
\end{tabular}

${ }^{1}$ Matéria seca; ${ }^{2}$ Probabilidade; ${ }^{3}$ Coeficiente de variação; ${ }^{4}$ Efeito linear. 
fósforo sérico. Já a redução linear $(\mathrm{P}<0,05)$ dos níveis séricos da enzima fosfatase alcalina com o aumento da inclusão da enzima fitase ocorreu devido sua ação sobre o fósforo fítico, aumentando a disponibilidade do fósforo. YOUNG et al. (1993), avaliando a inclusão de fitase em rações para leitões, também observaram redução dos níveis de fosfatase alcalina com o aumento dos níveis de fitase na ração.

\section{CONCLUSÃO}

Os níveis de 293, 307 e 255 UFT kg-1 de ração proporcionam, respectivamente, os melhores resultados de ganho de peso, consumo de ração e conversão alimentar de suínos alimentados com ração deficiente em fósforo.

\section{COMITÊ DE ÉTICA E BIOSSEGURANÇA}

Este trabalho foi submetido e aprovado pelo comitê de ética, sob processo n ${ }^{\circ}$. 015_2013 do Centro de Tecnologia Animal.

\section{AGRADECIMENTOS}

Agradecemos ao Centro de Tecnologia Animal (CTA), a Nutriave Alimentos e a Fundação de Amparo à Pesquisa do Espírito Santo (FAPES) por possibilitarem a realização dessa pesquisa.

\section{REFERÊNCIAS}

ADELOA, O. et al. Phytase-induced change in mineral utilization in zinc-supplemented diets for pigs. Journal of Animal Science, v.73, n.11, p.3384-3391, 1995. Disponível em: <http://www.journalofanimalscience org/content/73/11/3384>. Acesso em: 13 out. 2013.

APPLEGATE, T.J. et al. Effect of dietary calcium, 25 Hydroxicolecalciferol, or BIRD strain on small intestinal phytase activity in broiler chickens. Poultry Science, v.7, n.82, p.1140-1148, 2003. Disponível em: <http://ps.oxfordjournals. org/content/82/7/1140.full.pdf + html $>$. Acesso em: 23 out. 2013 doi: $10.1093 / \mathrm{ps} / 82.7 .1140$.

BRAGA, J.M. Avaliação da fertilidade do solo (ensaio de campo). Viçosa, MG: Imprensa Universitária, 1983. 101p.

BOWERS Jr., G. N.; McCOMB, R.B.A. Continuos spectrophotometric method for measuring the activity of sérum alcaline phosphatase. American Association of Clinical Chemists, v.12, n.2, p.70-89, 1966. Disponível em: <http://www.clinchem.org/ content/12/2/70.full.pdf + html $>$. Acesso em: 01 set. 2014

FIREMAN, F.A.T. et al. Enzimas na alimentação de suínos Ciência Rural, v.28, n.3, p.173-178, 1998. Disponível em $<$ http://dx.doi.org/10.1590/S0103-84781998000300029>. Acesso em: 21 nov. 2013. doi: 10.1590/S0103-84781998000300029.

JENDZA, J.A. et al. Escherichia coli phytase improves growth performance of starter, grower, and finisher pigs fed phosphorusdeficient diets. Journal of Animal Science, v.83, n.8, p.18821889, 2005. Disponível em: $<$ http://www.journalofanimalscience. org/content/83/8/1882>. Acesso em: 13 ago. 2013.
JONES, C.K. et al. Efficacy of different commercial phytase enzymes and development of an available phosphorus release curve for Escherichia coli-derived phytases in nursery pigs. Journal of Animal Science, v.88, n.11, p.3631-3644, 2010. Disponível em: $<$ http://www.journalofanimalscience.org/content/88/11/3631>. Acesso em: 21 nov. 2013. doi: 10.2527/jas.2010-2936.

QUIAN, H. et al. Effects of wide calcium: phosphorus on supplemental phytase efficacy for weanling pigs fed two dietary phosphorus levels. Journal of Animal Science, v.74, n.6, p.12881297, 1996. Disponível em: <http://www.journalofanimalscience. org/content/74/6/1288>. Acesso em: 12 jan. 2014.

RODRIGUES, V.V. et al. Nutrient reduction in rations with phytase for growing pigs. Revista Brasileira de Zootecnia, v.40, n.2, p.370-376, 2011. Disponível em: <http://dx.doi.org/10.1590/ S1516-35982011000200019>. Acesso em: 13 jan. 2014. doi: $10.1590 / \mathrm{S} 1516-35982011000200019$.

ROSTAGNO, H.S. Tabelas brasileiras para aves e suínos: composição de alimentos e exigências nutricionais. 3.ed. Viçosa, MG: UFV, DZO, 2011. 252p.

SARAIVA, A. et al. Níveis de fósforos disponíveis em rações para suínos de alto potencial genético para deposição de carne dos 30 aos 60kg. Revista Brasileira de Zootecnia, v.38, n.7, p.12791285, 2009a. Disponível em: <http://dx.doi.org/10.1590/S1516$35982009000700017>$. Acesso em: 12 jan. 2014. doi: 10.1590/ S1516-35982009000700017.

SARAIVA, A. et al. Available phosphorus levels in diets for swine from 15 to $30 \mathrm{~kg}$ genetically selected for meat deposition. Revista Brasileira de Zootecnia. v.38, n.2, p.307-303, 2009b. Disponível em: <http://dx.doi.org/10.1590/S151635982009000200013>. Acesso em: 13 jan. 2014. doi: 10.1590/ S1516-35982009000200013.

SELLE, P.H. et al. Consequences of calcium interactions with phytate and phytase for poultry and pigs. Livestock Science, v.124, n.1/4, p.126-141, 2009. Disponível em: <http://dx.doi. org/10.1016/j.livsci.2009.01.006>. Acesso 13 jan. 2014. doi: 10.1016/j.livsci.2009.01.006

SILVA, D.J.; QUEIROZ, A.C. Análise de alimentos: métodos químicos e biológicos. 3.ed. Viçosa, MG: UFV, 2006. 235p.

UNDERWOOD, E.J.; SUTTLE, N.F. The mineral nutrition of livestock. 3.ed. CABI Publishing, CAB International, Wallingford, 1999. 614p.

UNIVERSIDADE FEDERAL DE VIÇOSA (UFV). Sistemas de análises estatísticas e genéticas -SAEG. Viçosa, 2000. (Versão 8.0).

VARLEY, P.F. et al. Effect of dietary phosphorus and calcium level and phytase addition on performance, bone parameters, apparent nutrient digestibility, mineral and nitrogen utilization of weaner pigs and the subsequent effect on finisher pig bone parameter. Animal Feed Science and Technology, v.165, n.3/4. p.201-209, 2011. Disponível em: <http://dx.doi.org/10.1016/j. anifeedsci.2011.02.017>. Acesso em: 21 mar. 2013. doi: 10.1016/j. anifeedsci.2011.02.017

YOUNG, L.G. et al. Addition of microbial phytase to diets of young pigs. Journal of Animal Science, v.71, n.8, p.21472159, 1993. Disponível em: <http://www.animal-science.org/ content/71/8/2147.full.pdf+html>. Acesso em: 14 nov. 2013. 